\title{
The Use of Process Thinking in the Industrial Practice - Preliminary Survey
}

\author{
František KOBLASA, Eva ŠíROVÁ, Růžena KRÁLíKOVÁ
}

\begin{abstract}
Nowadays, the main implementation weakness of production management methods as Lean, Six Sigma or TOC lies with over focussing on particular method, so those methods are usually used solitary. Complex (i.e. process) approach is usually underestimated. This cannot be changed without changing the way of thinking within all levels of company's management. Process thinking (lean and holistic) becomes nowadays a challenge. This article is focussing on the use of basic principles of process thinking connected with design, technology and manufacturing logistics with emphasizing the role of standardization. There are debated, based on designed preliminary survey, possible key influences of management stuff etc. to implement and aid principles of standardization as defined by DFx (Design for $X$ ).
\end{abstract}

Keywords: design for logistics; lean methods; process innovation; process management; process thinking

\section{INTRODUCTION}

Nowadays, turbulent markets, hyper competition and supersonic changes are a widely discussed topic. Customers are more and more demanding and competition between companies is harder and more sophisticated.

The market changes are influencing also priorities of enterprise management. The focus on the customer (high delivery reliability) brings emphasis on the process (logistic) goals (short lead times, low inventory). There is also great pressure on the optimization of all enterprise processes and utilization of all enterprise resources as competition rises.

\subsection{Literature Overview}

Lean manufacturing is widely considered as a solution to before mentioned requirements. Applications of these principles make it possible to maintain requirements on process flexibility and to achieve higher process efficiency at the same time [1].

Generally, the systems such as Theory of constraints (TOC), Lean manufacturing and Six-sigma are used to optimize manufacturing systems. These systems are often used separately. Their combination and complex use can be more efficient and could offer much better results. Theory of constraints, which is usually applied as the first one, helps to find bottlenecks, which are constraining quality, enterprise effectively and the most importantly profit Lean manufacturing tool are than able to optimize process in given area [2]. While TOC goal is to increase main constrain throughput, lean thinking is trying to lower time component of the throughput time of both manufacturing (value added) and service (no value added) process [3].

It is not enough to manufacture faster and with lower expenses. Processes, which are not managed, can lead to production of large amount of defective parts [4]. Then the question of how to manufacture better i.e. better quality is coming up. Strategy of Six Sigma comes to reflect this requirement [5]. Tools, which are used in this strategy, are focussing mainly on common causes of faults minimizing number of defects, increasing quality of process output, lowering operation expenses, improving process efficiency and elimination of machine breakdowns caused by other than common effects [6].
Each of before mentioned system methods is unique and gives us verifiable outcomes to manage quality of process and products. However, it is necessary to use complex approach to improve its effects.

This led to complex method known as Lean Six Sigma which is focusing on the information and material flow as well as on improving value adding at each process [7].

It is necessary to develop effective system of management and control, which is able to detect process changes as soon as possible, so corrective measures can be established before a large amount of defective parts are manufactured [8] "optimum" [9]. There is used also so called holistic approach, besides known methods, to solve complex problems [10].

\subsection{Setting a Goal of the Article}

Therefore, the main requirements for manufacturing processes are speed, efficiency, performance, stability and return of investment. Lean, TOC (Theory of Constraints), Six Sigma, Management by ROI (Return of Investments), are approaches that are already commonly used by many companies (see e.g. [11, 12]). However, the problem of many companies is that they are focusing only on the implementation of the selected methods. There is still a widespread belief of "... we are lean because we have implemented 5S...".

However, this description responds rather to the conventional, operative problem-solving approach. The impact is focused on solution of the local problem, solving one problem after another. Lean (same as other philosophies/management approaches) is not only about methods execution.

Nowadays, the opposite approach, (i.e. the processholistic) is discussed. The main emphasis is put on global (comprehensive) approach to solve problems throughout the whole process (see e.g. [9]).

Every company is in its own way "unique" (business environment, production program, qualification and motivation of employees ...). Therefore, it cannot be clearly said that some of the management philosophy is just the "best" and applicable in "every company". It is, in practice, combination and adaptation of individual principles and methods. It is necessary to take into account specifics of the given enterprise. 
Another requirement, which plays an important role during finding effective solutions of enterprise tasks, becomes the process (holistic and lean) thinking. The process thinking of employees through the whole company (i.e. not just in logistics, but especially in the development and technology) can greatly aid the implementation of the so-called process management and other concepts of production/enterprise management.

Let us remind about some of the production paradigms:

- Performance of the process is determined by its bottleneck - however, bottleneck is not permanent, but it can float based on the current situation in the process (customer tact, cycle time, available equipment failures etc.).

- Process chain consists of interconnected individual cells - but they cannot be in the competition. Contradictory requirements are very common, for example diversity of production versus production batch size, short lead times versus maximizing resource utilization, nice design versus the number of items or parts manufacturability, etc.

Problems have to be solved in the context, i.e. it is necessary to:

- Discuss and compare various solutions according to different criteria and professions,

- Take into account the impact of preceding and following segments of the process.

Process approach to solve enterprises tasks is still not usual and its systematic use is rather rare. The implementation of the process approach (thinking) means enormous pressure on workers caused by the necessary change of required knowledge. There is higher demand of multi-functionality, interdisciplinarity and, in particular, ability to think and act in context as addition to the required higher special technical know-how.

The main goal of the article is to discuss nowadays level of the process thinking usage in the industrial practice of Czech companies. There will be briefly analysed selected approaches of DFx (Design For $x$ ) at first, which are reflecting requirements of process thinking in premanufacturing stages. Main focus will be put on usually underestimated DFL (Design for Logistics), DFE (Design For Environment) and DFSCM (Design for Supply Chain Management).

Techniques as Concurrent engineering and DF $x$ in the field of manufacturing and assembly (i.e. DFM - Design for Manufacturing, DFA - Design for Assembly, or its combination DFMA) are well known and used (see [13, 14]). Despite their benefits, they support only parts of the process and not the process as a whole, missing needs of logistics requirements.

The importance of design of manufacturing system integration as well as logistics in the product lifecycle is mentioned e.g. by Pernica [15]. He focuses on so-called vertical dimension of integration, which he describes as: "Linking and logistic aligning of the manufacturing and development, together with creating strategies and marketing, therefore interconnecting of enterprise (logistic) functions, from the operative level to the strategic one."

Generally, discussion about this topic is usually rather academic. Unfortunately, it can be said that systematic use of these approaches and techniques that are taking into account manufacturing process during development stage (as DFL - Design of logistics), is rarely used.

Let us point out some main principles of this methodology (see e.g. [16]):

- Economical packaging and transport (designing products so that there is better use of space, easier packaging, transport and storage, as is often cited example of IKEA),

- Parallel processing (the aim for such a design, which is allowing parallel/concurrent processing of manufacturing operations in order to shorten the production lead time),

- Standardization (the use of standard parts in multiple products).

Similar principles are used also in DFSCM (Design for Supply Chain Management) [17]:

- Standardization/number of parts minimization,

- Modularity,

- Versatility,

- Postponement - shifted product differentiation as configure-to-order (CTO).

One of the most underestimated fields in the "Design for" is the environmental approach (DFE - Design for Environment.

Let's remind ourselves of the basic rules of DFE[18, 19]:

- Cleaner Production,

- Less Material,

- Energy Saving,

- Recycling,

- Reuse,

- Long Lifecycle.

We can describe, on a simple schematic example (see Fig. 1), benefits of a process approach early in the development phase (i.e. taking into account logistics activities).
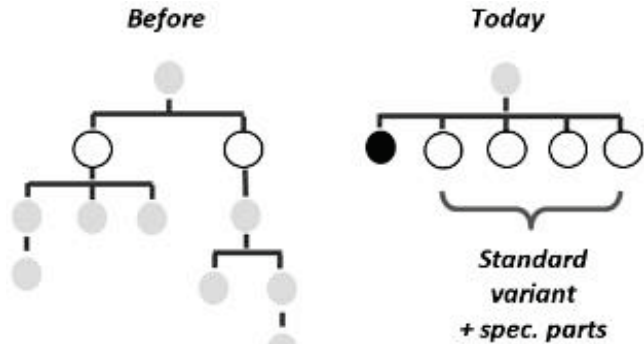

Figure 1 Structured BOM (bill of material) in the past and today - schematically

The lower number of elements and use of the standardized parts has great influence not only on material flow (purchasing, transport and manipulation, stocking, number of operations, number of manufacturing levels, etc.), but also on information flow (less data in the information system followed by easier data management, management of the material flow, data collecting and evaluation, order and billing process, stock management, manufacturing planning and scheduling etc.)

The benefits of process thinking can be briefly emphasized on selected examples: 
- New product design solutions together with new technologies can significantly reduce the complexity of production (20]),

- Moulds design adjustment can save manufacturing operation [21],

- The use of universal resource significantly reduces printer supplies ([22]),

- New packing method of incoming parts makes assembly significantly more effective [23].

Despite the obvious benefits of the described process approach there is still a part of developers and designers who are underestimating the role of logistics.

The main emphasis of this paper is then put on discussion about the preliminary survey results, the goal of which was to analyse the level of the use of process thinking (sometimes defined as holistic or logistic thinking) together with a possible influence of higher management in using and implementing basic rules, mainly in the field of standardization of before mentioned DFx.

Final discussion focuses on possible improvements and research direction.

\section{DESIGN OF PRELIMINARY SURVEY - APPLICATION LEVEL OF PROCESS THINKING}

The aim of the survey was also to gain basic information about the application level of process thinking in different companies. The attention was paid mainly to the level of the process/logistics within product development.

There were determined 3 main aspects, by expert estimation, to evaluate basic requirements of process thinking

- Use of standard parts,

- Use of other key factors influencing logistics processes such as the use of DFL, standard packages, targeted reduction of production levels, etc.

- Support of management to implement and process before mentioned requirements.

Survey was not performed in a traditional way but by combined way - through interviews held by personal visit combined with observation directly in the visited company.

Because it was a preliminary survey, a simple form of evaluation was chosen. As indicated, the answers were ranked according to the subjective assessment of the respondent into categories and the average was calculated from the responses - see a sample of flowchart in Fig. 4 and Fig. 5 where:

- $\quad I, J$ is value of given answer,

- $A, B$ is overall score,

- $n$ number of answers.

Within the interview were regarded pre-prepared and additional targeted questions that had arisen from the particular situation. During the interview there were given questions such as:

Standardization:

- Do you consider customer packaging during process of design?

- Do you intend to standardize packaging for the customer?
- Do you design modular or standard parts that are part of other products?

- Do you consult other departments or the customer about standardization?

Logistics:

- Do you use complex processing?

- Do you reduce the number of manufacturing levels?

- Do you use cooperation, and at what stage of production?

Management support:

- Does your management push on the use of the DFx principles?

- How is your management helping to use DFL principles etc.

- Do you use standard procedures in this area?

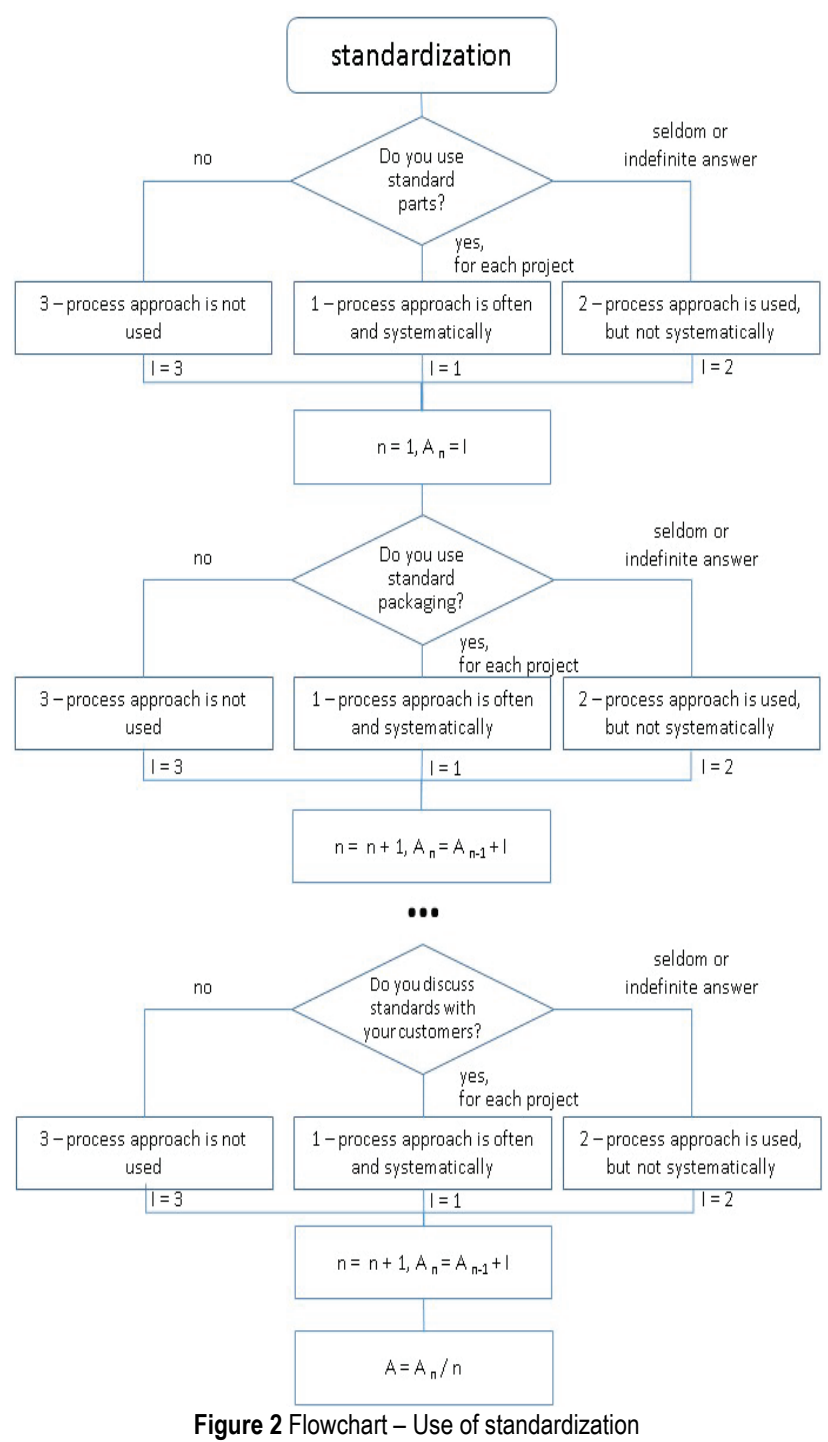

Knowledge gained from the visit of the company was subsequently subjectively categorized into three categories by the interviewer (see Fig. 4. and 5):

1 - Process approach is used frequently and systematically, with significant management support.

2 - Process approach is used, but unsystematically (e.g. on customer demand), with low management support.

3 - Process approach is used rarely or not at all, without the support of management. 
For a basic overview and fulfilment of the objectives was this segmentation sufficient. Exceptionally, in cases of doubt, the company ranked itself into higher category of process thinking exploitation.

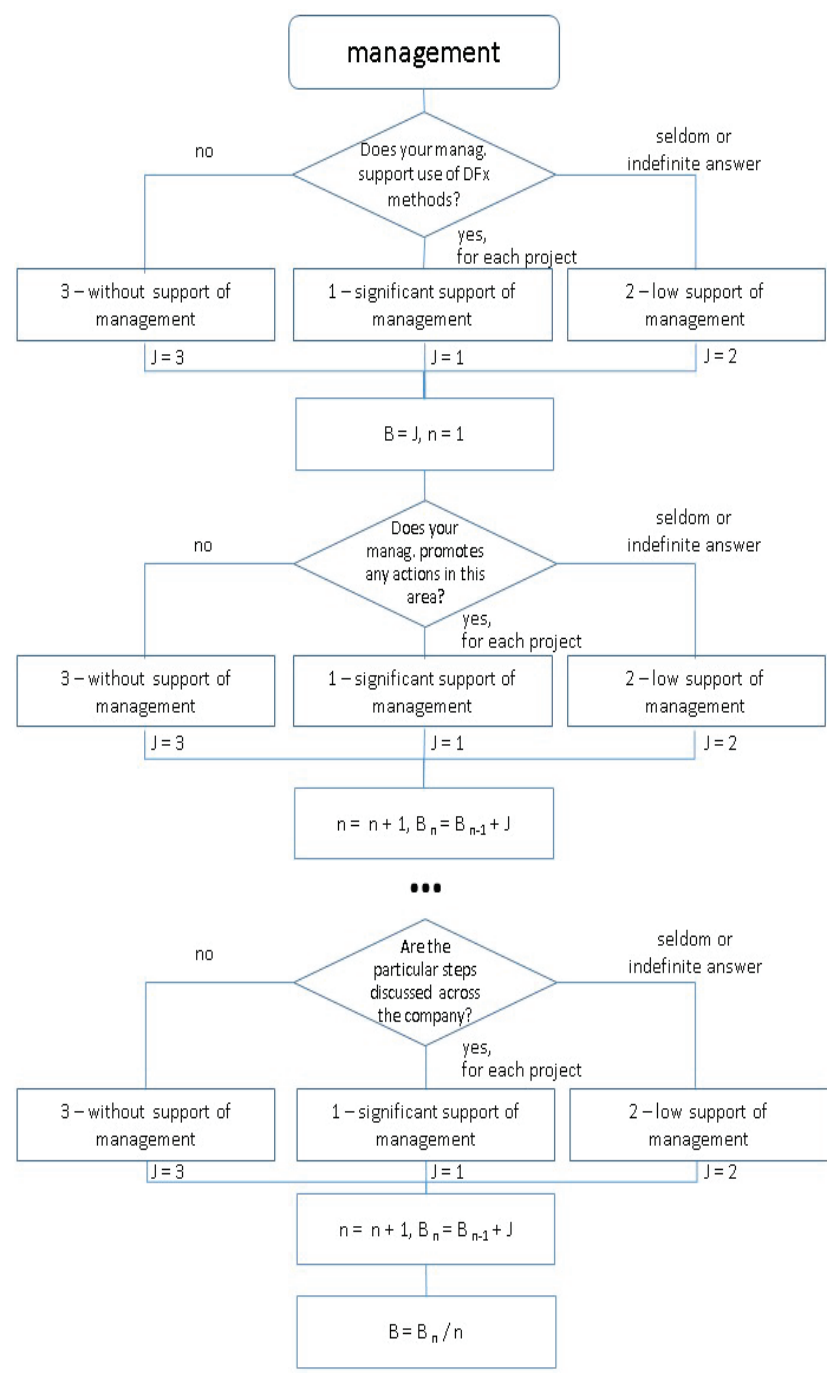

Figure 3 Flowchart - Support of management

The answers were assigned by subjective respondent evaluation and are represented by simple average. However, it is possible to use other approaches as setting weights of the answers and calculating the weighted average.

There were often contradictory answers according to the position of respondent in the company. Those bigger uncertainties (significant differences in the responses), were verified directly in the company by own observations to complete the survey. That is why survey was done by researchers familiar with the principles of process thinking.

Presented survey process may be much more difficult (time consuming and requiring highly skilled interviewer) and therefore it is more costly than traditional questionnaire. That is an undeniable disadvantage. However, interviewer is in direct contact with the respondents and is able to react to the current situation (e.g. by giving more accurate target questions).

The survey was performed by experienced staff familiar with the problems of process thinking.

Respondents were mainly designers and staff from logistics and technology and manufacturing departments.
The results of described survey are briefly shown in the following chapters.

\section{RESULTS EVALUATION}

Indicative survey was made on a sample of approximately 60 companies from the field of consumeroriented industry (divided into Automobile industry and other consumer goods segment, 33\%/67\% - see Fig. 4).

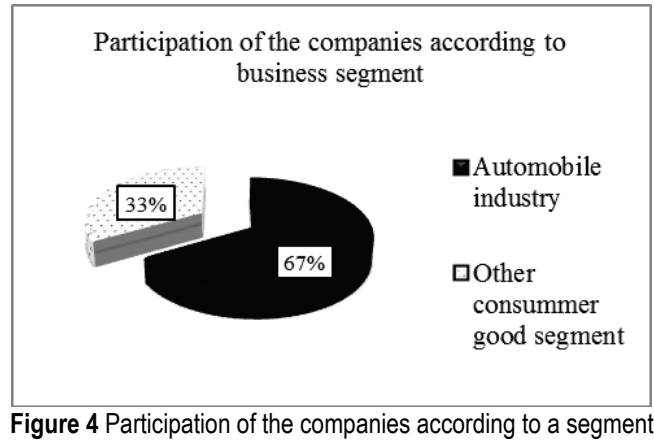

The results were divided into 2 parts: Standardization and Logistics. The first part "Standardization" monitors mainly the use of standard parts or modules (platforms) see Fig. 5.

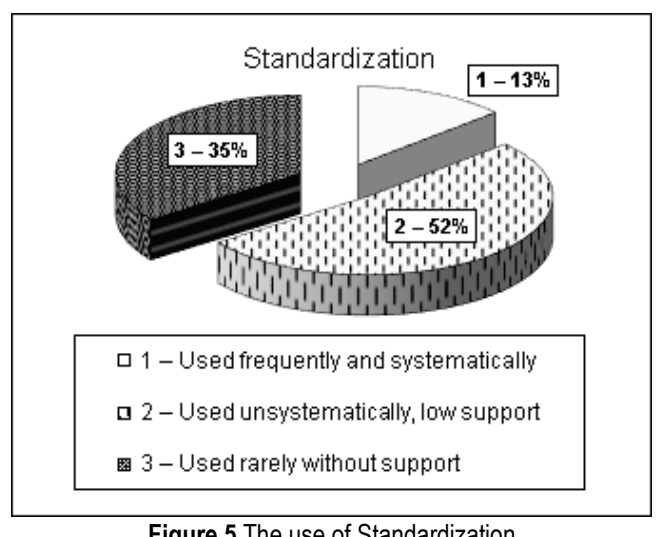

Figure 5 The use of Standardization

The use of standard parts is almost common. It is more initiative of enterprise's "lower levels" than systematic i.e. methodical approach (52\% of respondents claim that they are using process thinking but not systematically)

The second part "Logistics" monitors also other logistic processes as the use of standardized packing etc. see Fig. 6.

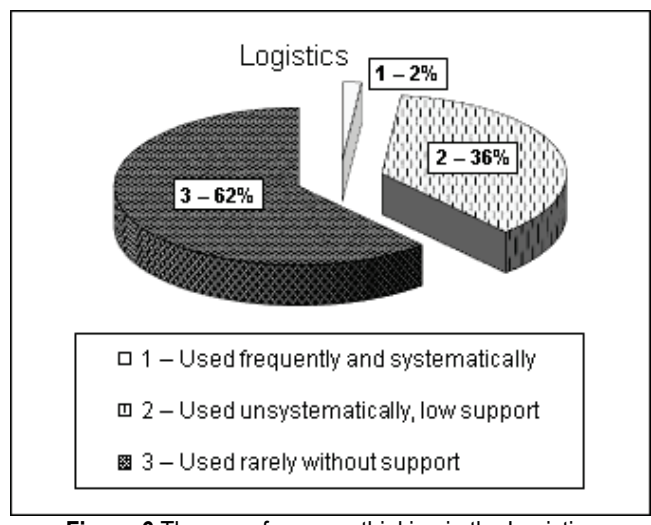

Figure 6 The use of process thinking in the Logistics 
As is it apparent from Fig. 5 and 6 there are great reserves in all fields of logistic, design of manufacturing systems and even manufacturing management. There is nearly no use of systematic (process) approach in those fields ( $62 \%$ of respondents are not using process thinking).

However, the analysis conducted in this way could be misleading. It is necessary to do more detail parsing. Although the results presented in Figs. 6 and 7 are sufficiently informative, they may seem too generalized. Therefore, a yet additional detailed analysis by type of consumer industries was divided into two groups Automobile industry versus other consumer goods industry.

The results and comparisons of the detailed analyses are shown in Figs. 7 to 11.

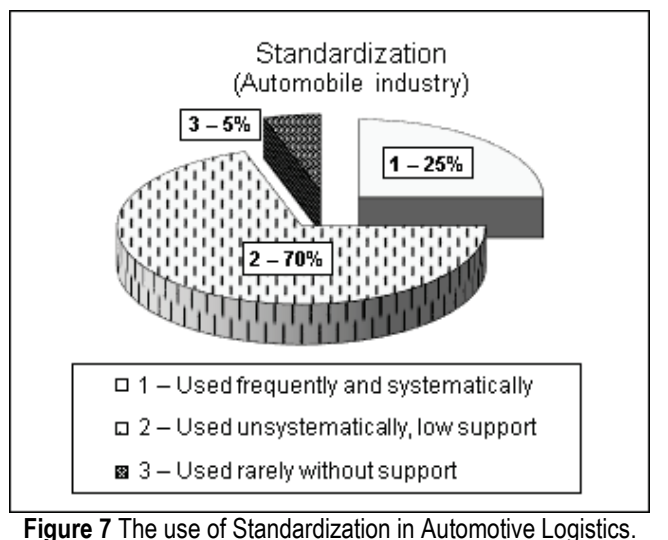

Nearly 95\% (see Fig. 7 sum of response category 1 and 2) of companies from Automobile industry use tools of standardization as they are forced by ISO/TS and other quality standards. However, it is used unsystematically and probably once per audited project.

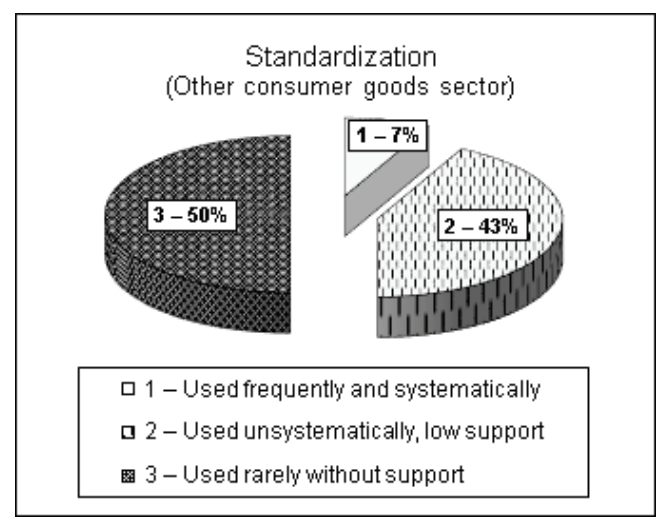

Figure 8 The use of the Standardization in other consumer goods sector.

Standardization is sometimes used (Fig. 8), but hardly ever systematically, in the case of other industry segments. That indicates low company culture, which in the case of Automobile industry is led by philosophies as Toyota Production systems.

The results of Logistic survey are shown in Fig. 9 and Fig. 10.

Logistics, in the case of Automobile industry (Fig. 10) is affected by the principles of DFx a bit less (sum of category 1 and 2 equals $75 \%$ comparing to $95 \%$ in the case of Standardization - see Fig 7). The biggest difference is in systematic approach (5\% compared with $25 \%$ ).

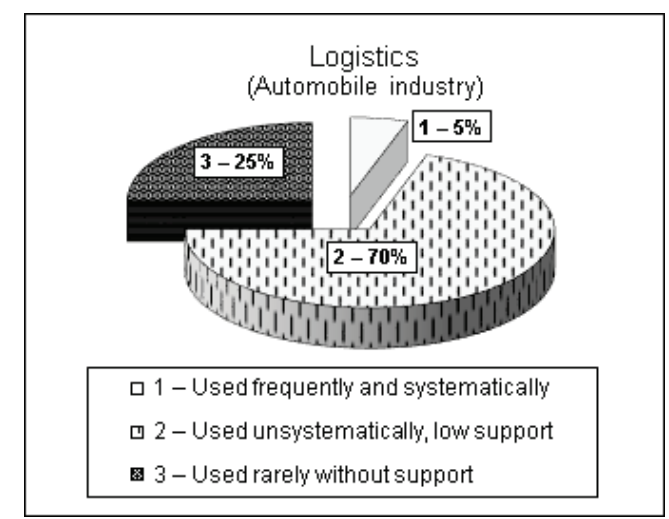

Figure 9 The use of process thinking in the Automotive Logistics.

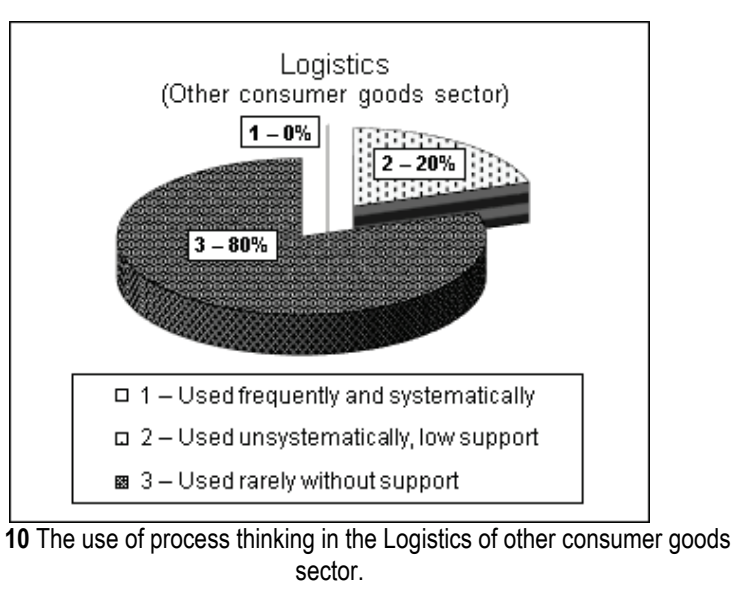

Methods mentioned in our review are occasionally used outside Automobile industry. Comparing to the Standardisation it indicates strong orientation on product rather than on the process.

Generally, the situation in automotive industry is quite satisfactory, as it is shown in Fig. 7 and 9. However, other industry is in the area of process thinking implementation mostly at the beginning (Fig 8 and 10). Comparing to the Standardisation (Fig 8 and 10) it indicates strong orientation on product rather than on the process (logistics).

The results of both the Process thinking and Standardization analysis show apparent imbalance between each field and use of unsystematic approach implementing various principles and methods. The Standardization focused survey results indicate that the companies are aware of the benefits of reducing the complexity of products and the number of different components, which gives a good prerequisite for the expansion of the process thinking.

Although this is only a preliminary research, the results indicate the direction in which further research should be focused. Activities which are increasing awareness of the process thinking and help with its implementation are e.g. a consistent assignment of the process to its owner and problem-based learning. It is necessary to focus on activities which are increasing awareness of the process thinking and helping with its implementation, i.e.:

- Detailed survey of the use of the process approach in small and medium enterprises.

- Developing a methodology for systematic implementation of process thinking and DFx 
approaches/methods in different types of enterprises and sectors.

- Development of motivational systems that will support the process thinking and implementation of process oriented DFx methods at all levels of the company. Those methods can be supported by reward theories, e.g. McGregor's theory that claims the necessity to support employee initiative through the allocation of powers and responsibility. This corresponds with the consistent assignment of the process owner.

\section{CONCLUSION}

The agility and innovation on one side, holistic and process approach to find solution of enterprise problems on other side - those are not just plain proclamations but necessities in nowadays world that help companies to compete.

The necessity of process (holistic, logistics) thinking is still growing. It is necessary to use methods and techniques that are aiding process thinking. That is important mostly in pre-manufacturing stages, because that is where the framework of functional enterprise processes is made.

Despite the fact that there are a number of methods in the field of DFx (e.g. DFMA, DFSS, DFS, DFL, DFE, see $[13,14,18,19])$, the only one frequently implemented is DFMA as results are suggesting. The others are used solitary (as survey indicates) and in the non-standardized matter. That is caused also by unwillingness to change the proven ways and by constant effort to change manage things just by "local" solution - e.g. conventional thinking.

The most important is the indisputable role of senior and middle management. On the one hand, awareness of process management thinking and practice and use of appropriate methods by trainees and training programs can be raised; on the other hand using appropriate motivational programs can increase initiative and motivation. Simulation games take real business situation as a model and render its main features, problems, roles and the dilemma. In this simulation process, simulation games imitate reality while reducing the complexity of the system to a manageable level. This can be a response to calls for in-depth studies of production and operation analysis. The resources used in the mentioned activities should be returned not only by increased competitiveness, but should be also positively reflected in the economic indicators.

Another major impulse for the process thinking development should be the creation of a methodology to support the systematic implementation of process thinking and process oriented DFx methods at all levels of the company.

Mentioned pressure on a holistic process approach to solve business tasks must be reflected in lectures at universities. It is necessary to establish and develop such methods and approaches that promote and develop the process thinking, such as Problem-Based Learning or cooperative study programs.

\section{Acknowledgements}

The research reported in this paper supported specific university research within the student grant competition TUL (Project 21130) - Research and development in the field of 3D technology, manufacturing systems and automation. This paper is dedicated to our bellowed friend doc. Dr. Ing. František Manlig.

\section{REFERENCES}

[1] Bhamu, J. \& Singh Sangwan, K. (2014). Lean manufacturing: literature review and research issues. International Journal of Operations \& Production Management, 34(7), 876-940. https://doi.org/10.1108/IJOPM-08-2012-0315

[2] Jasti, N. V. K. \& Kodali, R. (2015). Lean production: literature review and trends. International Journal of Production Research, 53(3), 867-885. https://doi.org/10.1080/00207543.2014.937508

[3] Danese, P., Manfè, V., \& Romano, P. (2018). A Systematic Literature Review on Recent Lean Research: State-of-the-art and Future Directions. International Journal of Management Reviews, 20(2), 579-605. https://doi.org/10.1111/ijmr.12156

[4] Conger, S. (2015). Six sigma and business process management. In Handbook on Business Process Management 1. Springer, Berlin, Heidelberg, 127-146. https://doi.org/10.1007/978-3-642-45100-3_6

[5] Krueger, D. C., Mellat Parast, M., \& Adams, S. (2014). Six Sigma implementation: a qualitative case study using grounded theory. Production Planning \& Control, 25(10), 873-889. https://doi.org/10.1080/09537287.2013.771414

[6] He, Z. \& Ngee Goh, T. (2015). Enhancing the future impact of Six Sigma management. Quality Technology \& Quantitative Management, 12(1), 83-92. https://doi.org/10.1080/16843703.2015.11673368

[7] Furterer, S. L. (Ed.). (2016). Lean Six Sigma in service: applications and case studies. CRC Press. https://doi.org/10.1201/9781420079104

[8] Jacobs, B. W., Swink, M., \& Linderman, K. (2015). Performance effects of early and late Six Sigma adoptions. Journal of Operations Management, 36, 244-257. https://doi.org/10.1016/j.jom.2015.01.002

[9] Monostori, L., Valckenaers, P., Dolgui, A., Panetto, H., Brdys, M., \& Csáji, B. C. (2015). Cooperative control in production and logistics. Annual Reviews in Control, 39, 1229. https://doi.org/10.1016/j.arcontrol.2015.03.001

[10] Jovanović, M., Zupan, S., Starbek, M., \& Prebil, I. (2014). Virtual approach to holonic control of the tyremanufacturing system. Journal of Manufacturing Systems, 33(1), 116-128. https://doi.org/10.1016/j.jmsy.2013.07.005

[11] Bhamu, J. \& Singh Sangwan, K. (2014). Lean manufacturing: literature review and research issues. International Journal of Operations \& Production Management, 34(7), 876-940. https://doi.org/10.1108/IJOPM-08-2012-0315

[12] Singh, K. \& Misra, S. (2018). Theory of Constraints for Managing Downstream Supply Chain in Indian FMCG Sector: A Literature Review. Journal of Supply Chain Management Systems, 7(1).

[13] Murali, G. B., Deepak, B. B. V. L., \& Biswal, B. B. (2017). A Novel Design for Assembly Approach for Modified Topology of Industrial Products. International Journal of Performability Engineering, 13(7), 1013. https://doi.org/10.23940/ijpe.17.07.p2.10131019

[14] Thompson, M. K., Jespersen, I. K. J., \& Kjærgaard, T. (2018). Design for manufacturing and assembly key performance indicators to support high-speed product development. Procedia CIRP, 70, 114-119. https://doi.org/10.1016/j.procir.2018.02.005

[15] Pernica, P. Logistický management. Teorie a podniková praxe. 1. vyd. Praha: RADIX, 1998, $660 \mathrm{~s}$ (No. s 384). ISBN 80-86031-13-6. 
[16] Abdallah, S. B., Aidi, M., Zouari, A., \& Maalej, A. (2015). Systems engineering used for logistics integration in product design. Journal of Traffic and Logistics Engineering, 3(2). https://doi.org/10.12720/jtle.3.2.185-188

[17] Tolonen, A., Haapasalo, H., Harkonen, J., \& Verrollot, J. (2017). Supply chain capability creation-The creation of the supply chain readiness for a new product during product development process. International Journal of Production Economics, 194, 237-245. https://doi.org/10.1016/j.jpe.2017.09.007

[18] Arnette, A. N., Brewer, B. L., \& Choal, T. (2014). Design for sustainability (DFS): the intersection of supply chain and environment. Journal of Cleaner Production, 83, 374-390. https://doi.org/10.1016/j.jclepro.2014.07.021

[19] Poulikidou, S., Björklund, A., \& Tyskeng, S. (2014). Empirical study on integration of environmental aspects into product development: processes, requirements and the use of tools in vehicle manufacturing companies in Sweden. Journal of Cleaner Production, 81, 34-45. https://doi.org/10.1016/j.jclepro.2014.06.001

[20] Modrak, V., Soltysova, Z., Modrak, J., \& Behunova, A. (2017). Reducing Impact of Negative Complexity on Sustainability of Mass Customization. Sustainability, 9(11). https://doi.org/10.3390/su9112014

[21] Govorkov, A. \& Zhilyaev, A. (2016, April). The estimation technique of the airframe design for manufacturability. In IOP Conference Series: Materials Science and Engineering (Vol. 124, No. 1, p. 012014). IOP Publishing. https://doi.org/10.1088/1757-899X/124/1/012014

[22] Allon, G., Van Mieghem, J., \& Kolesov, I. (2017). HP Product Variety Management. Kellogg School of Management Cases, 1-7. https://doi.org/10.1108/case.kellogg.2016.000154

[23] Betancur-Muñoz, P., Osorio-Gómez, G., Martínez-Cadavid, J. F., \& Duque-Lombana, J. F. (2014). Integrating Design for Assembly guidelines in packaging design with a contextbased approach. Procedia CIRP, 21, 342-347. https://doi.org/10.1016/j.procir.2014.03.173

\section{Contact information:}

František KOBLASA, PhD, Ing

Technical University of Liberec - Faculty of Mechanical Engineering

Department of Manufacturing Systems and Automation

Studentská 1402/2, 46117 Liberec 1, Czech Republic

frantisek.koblasa@tul.cz

Eva ŠíROVÁ, PhD, Ing.

Technical University of Liberec -The Faculty of Economics

Department of Business Administration

Studentská 1402/2, 46117 Liberec 1, Czech Republic

eva.slaichova@tul.cz

Růžena KRÁLíKoVÁ, Assoc. Prof. PhD, Ing.

Technical University of Košice - SjF- KE

Letná 9, 04200 Košice, Slovak Republic

ruzena.kralikova@tuke.sk 